\title{
THE FORMAL STRUCTURE OF PRACTICAL RATIONALITY
}

\author{
LYDIA DE TIENDA PALOP \\ Universidad Complutense de Madrid
}

\begin{abstract}
The concept of rationality is strongly normative. Indeed, qualifying an action as rational implies demarcating spaces of inclusion and exclusion that have a practical impact. However, the notion of rationality is not fully explained. In this article I intend to clarify the constitutive elements of the formal structure of practical rationality in order to facilitate its conceptualisation.
\end{abstract}

KEY WORDS: Rationality; Model; Deliberation; Optimisation; emotions.

\section{La estructura formal de la racionalidad práctica}

RESUMEN: El concepto de racionalidad es fuertemente normativo. De hecho, calificar una acción como racional implica demarcar espacios de inclusión y exclusión que poseen impacto a efectos prácticos. Sin embargo, la noción de racionalidad no está completamente explicada. En este artículo, me propongo clarificar los elementos constitutivos de la estructura de la racionalidad práctica con el fin de facilitar su conceptualización.

PALABRAS CLAVE: racionalidad; modelo; deliberación; optimización; emociones.

\section{RATIONALITY AS A MULTILATERAL PHENOMENON}

Rationality is an extensively used word, especially in current times, and, as such, has become hackneyed. There is talk of the rationality of the media, the rationality of subjects, of rationality in economics, in law and in other disciplines. Agents are classified as rational depending on their decisions, actions and beliefs, and even systems, models and processes are also assessed according to their rationality. Everyday life is loaded with rationality and subject to rationalisations. But what is rationality? What is its nature? What does it mean to qualify something as rational? Are rationality and reason the same? Can a thinking being be equated with a rational being? Rationality is said of many things, sometimes with greater conceptual success than others, and although it is difficult to give a concrete and uniform definition of the term, what can be accepted is that describing something as «rational» entails a whole axiological universe and an obvious normative demarcation.

One appropriate way of tracing its definition could be to reconstruct the concept from the varied perspectives and theories of different authors. The difference between the ways of understanding what rationality is goes beyond the question of the degree of terminological nuance; rather it involves both theoretical and decisive practical implications. In fact, although various thinkers have often used the term "rationality» interchangeably and synonymously with reason or thought, today, despite the blurred boundaries between the two terms, the word rationality contains certain peculiarities that hamper its consideration as a synonym of reason. 
I do not intend to exhaustively determine the definition of the term in these pages. Perhaps this is a wholly misconceived task from the start, since if we understand language as a dynamic product of a living history of thought, we must grant some flexibility to the analysis and a degree of independence to each author that uses the term. This presupposes that each thinker contributes in a particular way to generating the intentional complexity of words, by creating new significant demarcations. What I seek is an elucidation of the term to deepen the understanding of our praxis, because the word is what generates the laws of our human world. The meaning of a word implies a whole conceptual universe that may be translated into concrete practices. Our praxis is the product of our thinking and the concepts on which it is built. In short, what is intended in this brief essay is not to outline the concrete, precise and immutable meaning of what «substantive rationality» is, but to understand what the defining notes of rationality are and, therefore, what may be configured as the archetype of the «rational» in a practical sense. Therefore, it is necessary to make a qualitative leap in research and reformulate the question of the search for the concept of «rationality», by turning it into the search for its formal structure and not just its substantive content.

\section{Concept versus Rationality Model}

Brown, in his work Rationality ${ }^{1}$, analyses what he calls the classical model of rationality in reference to the positivist model that emerged from the Vienna Circle, which was highly influential in shaping practices across the disciplines during the twentieth century. Brown understands the model as «the result of the attempt to draw and construct a clear and distinct definition of the given concept $»^{2}$. He argues that concepts are invented and built over time, have a history and, therefore, it is very difficult to develop a precise definition. Although dictionaries and encyclopaedias are indeed a great help, since they compile information multilaterally, they do not exhaust the concept $^{3}$. Despite the detailed definitions that can be gathered, it is no easy task to specify the semantic content of some terms, as is the case with the concept of rationality. But in addition to this insight from Brown, in the case of concepts such as rationality, an additional question emerges that gives them a particular conceptual difficulty. Some words have the particular characteristic of being strongly normative, of creating spaces of axiological demarcation that entail a set of connotations of an evaluative nature. This circumstance implies that the description produced through the use of the concept has a practical repercussion and, therefore, these concepts are

Brown, H. I., Rationality, New York: Routledge, 1988.

Ibid., p. 182.

Ibid., pp. 178-82. 
bearers of an evaluative dimension that is reflected in the adoption of a nonneutral attitude.

For this reason, in my view, currently when referring to rationality, instead of talking about the "concept of rationality» to determine the content of a particular notion of rationality and, therefore, the substantive criteria that apply to qualify a practice as rational or irrational, it would be more appropriate to speak of a «rationality model». The notion of model brings different nuances from those denoted by «concept». When expressions describe a practice as rational, they are not referring solely to a concept, but construct a definition with an evident normative burden — which can also be variable - apt to be applied to different fields and that may have practical repercussions.

The model is that archetypal construct with two components: a) versatility, in that it can be applied to manifold issues according to need; and b) normativity, namely, it is canonical. The model demarcates criteria for inclusion and exclusion of what can be subsumed within it. The "model» of rationality is contingent in terms of its content; it can be developed, replaced or perfected and it is relative to the historical and cultural context in which it is embedded. The "concept» is subtly different; it may have greater intentional richness. Its purpose is descriptive and comprehensive, and unlike the model, it is not expressly directed to specify criteria of application. The concept can evolve and it is undeniably a creator of reality in the way it subsumes material content into the idea. However, although this can be contingent, the concept can be perpetuated in its formal notes even though its content may have been modified. Not so with the model. The model is rooted in the concept to generate a semantic universe based on an axiological system that, once discarded, disappears and is replaced by another model. Therefore, what I pursue in this essay is to point out that the formal structure of the concept which can be common to any model, if a certain semantic integrity of the concept is preserved. It is true that the formal structure of its content cannot be completely split off, because if this were to happen we would be faced with a phenomenon of a different kind: the referent will have changed but the linguistic sign is maintained. This phenomenon is different from the homonymy, which refers to the phonetic and graphic identity of words but with different meaning and etymology. In the case referred to here, the etymological origin is similar, but this is what becomes misleading: although the linguistic word is identical the resulting word is very different because the meaning is different. However, if we grant that it is possible to find a balance between certain formal features that, in turn, only in a formal sense can be understood as substantive characteristics of the concept, then it can be said that there is no extinction and creation of a new word, but that the event occurred is a transformation of the model, in this case, of rationality in its practical sense.

It remains to be set out, for the sake of proceeding to clarify what I pursue in these pages, what is to be understood by that supposed material content as far as the formality of the concept is concerned. The answer would be that the formal material that can be retained to continue talking about the same term 
are those features that allow the intelligibility of the concept between subjects separated by temporal spaces over the phylogenetic course. One could only speak of the same word if, in a temporal segment, ceteris paribus, delimited by two etymological milestones, subjects could participate in effective communication. Although a phylogenetic history of the concept can be traced, in a temporal unit such as the one I propose, two interlocutors separated by an extended period of time will barely be able to understand the word in the same way, even though it has the same etymological root. Therefore the formal structure of the term cannot be dissociated from its material essence and, thus, cannot be sustained universally and perpetually.

\section{THE ELEMENTS OF THE FORMAL STRUCTURE OF PRACTICAL RATIONALITY}

Rescher has studied the notion of rationality ${ }^{4}$ in depth and provides a sufficiently flexible analysis to adapt to the formal requirements of such a concept for the different disciplines ${ }^{5}$. His theses are applicable to both the theoretical and the practical dimension of rationality and, above all, insightfully characterise the concept that is commonly used in contemporary intellectual contexts. I will depart, for my analysis, from the first meaning Rescher gives the term in which he argues that «rationality consists of the proper use of reason to make choices in the best possible way» ${ }^{6}$. In my view, this apparently simple definition contains a whole complex conceptual universe, which I will proceed to unravel in order to trace the features of the structure of rationality in its contemporary version:

1) Firstly, following this definition, in order for rationality to be predicated upon something or someone, it becomes evident that it requires the exercise of an activity. This activity pertains to a certain species. It is intimately connected with the faculty of reason and its particular practical function. It is not, therefore, any activity, a more or less mechanical movement, such as raising and waving a hand in greeting, but a properly intellectual activity.

2) Secondly, it is necessary to presuppose the factum of a structure of possibilities, more or less finite, that require the intervention of reason

4 Rescher, N. (1988). Rationality: a philosophical inquiry into the nature and the rationale of reason. Oxford: University Press.

5 Rationality, strictly speaking, refers only to a formal characteristic of individual actions, the most characteristic quality of which is "consistency». However, the "substantial rationality», which is what ultimately interests us, is closely related to the notion of «judgement»: Cfr. Elster, J., Uvas amargas: sobre la subversión de la racionalidad, Barcelona: Edicions 62, 1988, pp. 7-65.

6 RESCHER, Rationality: a philosophical inquiry into the nature and the rationale of reason, op. cit., p. 1. 
so that choice can be performed effectively. Rationality is a synthetic proposition: in order to be predicated, irrationality must also be possible.

3) Thirdly, it requires an idea of good, which has a double function: a) as the ultimate goal of the activity that prefigures a procedural logic; and 2) as the guiding criterion that allows demarcation or evaluation between what is rational and what is not. Rationality, therefore, must be perfectionist.

Other definitions given by the same author contribute to further outline the concept: rationality is «the intelligent pursuit of appropriate ends»; «To act rationally is to make use of one's own intelligence to understand what is the best thing to do in certain circumstances»; "Rationality is, therefore, a question of what is best done deliberately with the means that one has ${ }^{7}$. According to these commonly accepted definitions, if rationality is understood as «the intelligent pursuit of appropriate ends» ${ }^{8}$, this, in my opinion, must necessarily entail the exercise of two intellectual operations: a) deliberation and b) optimisation. Both activities have a processual nature, considering that they are two exercises that must be carried out in a time lapse.

\section{a) Deliberation.}

What does it mean to deliberate? Arenas-Dolz reconstructs the etymology of the term deliberation, from its Greek origin in the Aristotelian corpus under the term bouleusis ( $\beta$ ov́ $\lambda \varepsilon v \sigma ı)$ ), to the double Latin root for which it was translated as consilium and as deliberatio ${ }^{9}$. The concept of contemporary deliberation has its roots in the theses of Aristotle, which he examines fundamentally in Book III of Nicomachean Ethics and Rhetoric ${ }^{10}$. Aristotle distinguishes between voluntary and involuntary actions (EN 1110a). Once the philosopher has defined what a voluntary action is, he goes on to deal with the subject of «choice» (proairesis, $\pi \rho 0 \alpha \iota \rho \varepsilon \delta 1 \varsigma)$, which he conceives as a voluntary action (EN 1111b 5-10) and related to the terms of desire (epithymia, غ̇лı $\theta v \mu$ ía), passion (thymos, $\theta 0 \mu$ ós),

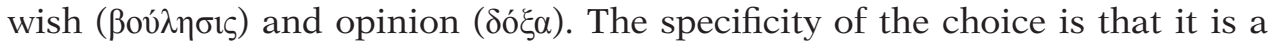
voluntary action preceded by deliberation, since the choice implies reasoning and some thought process (EN 1111b). In fact, Aristotle himself clarifies that the expression to proaireton ( before other things, that is to say, that it has a certain priority. The deliberation, in short, is a process of thought, an activity that is properly reasoning and has some distinctive notes of its own:

7 Ibid., p. 1.

Ibid., p. 2.

9 Arenas Dolz, F., «Hermenéutica, retórica y ética del lógos: deliberación y acción en la filosofía de Aristóteles», Tesis doctoral, València: Universitat de València, Servei de Publicacions, 2007, p. 346.

10 Aristóteles, Ética a Nicómaco, Madrid: Centro de Estudios Políticos y Constitucionales, 1999 y Retórica Madrid: Alianza Editorial, 2007. 
1) It is an intellectual process that has a clearly practical objective, namely transformative or creative, in as much as: a) one does not deliberate about things that are eternal (EN 1112a); about the eternal things there is a kind of intellectual operation, but not deliberation properly; $b$ ) there is no deliberation about necessary or natural things; c) nor about what is by accident or chance. One deliberates precisely about what may be affected by our agency. We deliberate about things that are under our control and are achievable through action. But also, we do not deliberate about everything that can be affected by our actions, but only "on some things» and, among those things, about "the ones that do not always produce the same results». Therefore, deliberation is performed on matters in which, although there is a certain subjection to rules, governed by a good or idea of good, are uncertain or the issue is indeterminate. Therefore, Aristotle understands that "we do not deliberate on the ends, but on the means». Aristotle also states that we only deliberate about the "possible» and by possible he means «that which is capable of being realized by our agency». In short, this task requires a weighting and evaluation and leads to the choice of a set of possibilities.

2) Deliberation is a research activity that seeks conclusions applicable to actions. When deliberating, one follows the process typical of a research task, similar to the analysis of a diagram. In fact, it seems that not all research is deliberation, such as mathematical research, but that all deliberation is definitely research. And the last step in the analysis is manifested as the first in the execution of the design (EN 1112b). The proper ground of deliberation is to discover what the actions are that one has the capability to perform and that tend towards a good. The deliberation pauses when it comes to the particular event, because otherwise a process would begin ad infinitum. Although the object of the choice and that of the deliberation is the same, they differ in that once it has been chosen, the object becomes something determined by virtue of the previous deliberative process: the object of the choice is something that is possible for us to desire after we have deliberated. Therefore, with good reason, Aristotle maintains that choice is a deliberate desire for something within our reach (EN $1113 \mathrm{a}$ ).

\section{b) Optimisation}

The other process that rationality necessarily involves is optimisation. If we assume Rescher's thesis that the appropriate rational procedure in problem solving is to strive to achieve the best possible solution with the data available ${ }^{11}$, in my view, optimisation is a process that should contain the following structural constituents:

11 RESCHER, Rationality: a philosophical inquiry into the nature and the rationale of reason, op.cit., p. 22. 
1) The existence of a cluster of possibilities. That is, of truly viable and feasible alternatives; otherwise, we would only find ourselves facing something that is triggered «by necessity» and that does not require any intervention.

2) The presupposition of a reason, understood as an intellectual faculty.

3) An activity of that entity-reason that processes and evaluates the circumstances; in this sense, the reason is also an informative-sensitive faculty.

4) A guiding idea of good. Rationality is therefore perfectionist, since it is a teleological activity.

The rational necessarily follows the maxim of «achieving the best possible», contingent on the circumstances, the context and the other factors involved. Rationality implies a solid normative component: that of realising not only "the good», but the best, under certain circumstances and limits, and this is its outstanding characteristic; otherwise it would be a contradictio ad adjecto. Rescher posits in the same way that «the rational thing to do at the time of resolving a question is to make the best use of all the relevant information that we have ${ }^{12}$. In this way, optimisation requires processing all the information available to us. It does not matter if this information is defective, in that it is scarce or not true. The important thing is that it is considered true by the one who is performing the optimisation process to make the decision. A different question is the fact that the more information that is possessed and the more truthful it is, the more effectively the result of the choice will guarantee the objective, depending on the purposes of that choice. This consideration informs us about the effectiveness of a procedure, but does not help to clarify the rationality that I propose, although the veracity of the information does have a function as an external correction criterion for evaluating rational actions. In any case, it is necessary to distinguish between rationality and efficiency. An action can be perfectly effective, even though it has been carried out on an irrational basis, and vice versa: acting according to a strict protocol of rationality, one can err in the successful attainment of the goal even when being rational. What I emphasise is that the optimisation process, which is essentially different from rationality, is related to efficiency in a peculiar way. The relevance of optimisation does not have to do with the effective achievement of the good, but with the choice of means to achieve the end, namely, according to the dictates of the reason to attain what is considered best. Therefore, it is linked to the rules dictated by reason guided by an idea of good, independently of the effective fulfilment of the object.

Wisely, Rescher states that «rationality is the art of the possible - a question of doing the best that is possible in the average of the circumstances in which the agents work»; "if we had "complete information" and, in particular, we

$12 \quad$ Ibid., p. 23. 
knew how our decisions would affect the facts, that is, how the facts would be depending on one decision or another, then the rational decision-making plans would be something very different from what they currently are ${ }^{13}$. Rescher is thus pointing out that in this world we are obliged to «decide, operate, plan and act in the light of incomplete information ${ }^{14}$. We do not know what the consequences of our actions will be; all we can do is «be rational in the circumstances as best we can determine to be» ${ }^{15}$. The outcome that derives from what we have said, which conflicts with many of the theses upheld so far, especially from the field of positive science, is that rationality «under ideal conditions» does not make sense. That is to say, one can only speak of rationality in practical matters, under imperfect circumstances. According to Rescher, this is the only concept of meaningful rationality: «If rationality must be something that we can really apply, then it must be something that claims that we can undertake it under sub-ideal conditions ${ }^{16}$. Therefore, rationality is evidently practical, something that always looks at the possibility and not at the need. Although I argued above that rationality was perfectionist, this is not to say that it is perfect, because it does not operate under ideal conditions. This statement is consistent with Rescher's claim that "rationality is a question of optimization subject to the information bases» ${ }^{17}$. In this sense, "rationality is not a question of absolute optimization, but of circumstantial optimization, not of doing what is the best thing unconditionally, but of doing the best that can be done in the circumstances -including the informational circumstancesthat matter» ${ }^{18}$.

\section{THE EMOTIONAL DIMENSION OF PRACTICAL RATIONALITY}

There is still more to be revealed in the formal structure of the concept of practical rationality. We have superficially mentioned two fundamental activities that have their relevance in the unavoidable dual exercise of deliberation and of optimisation: weighting and prioritisation. It is precisely at this point that the affective dimension of the human being comes into play, that psychophysical device that essentially distinguishes us from artificial intelligence: namely, emotions.

Emotions are precisely the tool that enables the human being to prioritise; emotions advise and inform human beings about their desires, needs, insufficiencies and objectives in a peculiar way. Like everything properly human, they are not exempt from complexities and dualisms; they are not configured as

\footnotetext{
13 Ibid.

14 We observe how, although from a different perspective, Rescher is close to the line of Spanish philosophy, especially to authors such as Ortega y Gasset and Zubiri.

15 Ibid.

16 Ibid.

17 Ibid., p. 25.

18 Ibid., p. 29.
} 
an exact technological measurement tool, but they are a practical device that acts as a kind of thermostat to regulate decision making in practical matters. Many authors affirm that emotions are «rational» in a sense closer to the first etymological meanings of rationality, such as coming from reason or related to it. This affirmation no longer refers to the normative side of reason, which would be rationality proper, but to the quality related to the faculty of reason for its cognitive function. Effectively, emotions provide a type of information to the subject who experiences them, but the content of this cognition is of a particular type: it is evaluative. Emotions, in fact, possess a cognitive- evaluative substratum that is essential for them to be aroused and, in this sense, they are rational even though they are manifested somatically. They are not a pure reflex, nor are they exclusively triggered as a result of physiological chemical processes, as William James argued. Indeed their rational nature does not come only from their cognitive capacity as value sensors, but they are rational and contribute to practical rationality because, in my view, they have a normative dimension. Therefore, I argue that one can describe an emotion as irrational in the sense that it does not adjust to the criteria dictated by rationality, but they are never irrational in a cognitive sense. Emotions allow privileged access to the constellation of values that a subject possesses and it is precisely this virtuality that provides human beings with a biological scheme of objectives, in light of which we prioritise and ponder in the exercise of our praxis, which artificial intelligence lacks. Therefore, both the deliberation exercise and the optimisation exercise, which make it possible to classify an action as rational, require of the emotional component that it can be carried out.

One might still argue that, effectively, robots are not emotional beings, but they embody rationality par excellence. However, I believe this argument contains some basic errors. The present article does not aim to resolve what rationality is in an absolute sense, namely, in its theoretical and practical dimension, but only to clarify the components of the practical side of rationality. The objects of rational activities in a practical sense are the actions and these are about the contingent, which can take multiple forms as I have pointed out. The good that regulates the choice in a practical action - and therefore makes it the preferred choice- is configured as the value that rational validity itself provides for the action. Because the fact that the good, when perceived by the subject, may be capable of generating an emotion implies that this good is invested with value for the emotional subject. An internal biological warning alerts the subject to the relevance of the object, unleashing a biochemical revolution that is configured as a motivating element of a unique nature. The repressive exercise of emotion is an important sacrifice of physical and mental discipline that violates the nature of the subject. With this I am not claiming that all emotion should follow its course freely, because uncontrolled emotions can be highly destructive, but I am assuming the epistemological value of emotions in relation to practical rationality. It is not rational to choose what produces anger, distress or sadness; on the contrary, it is rational in a practical sense to choose what produces joy or compassion. Emotions provide the subject with valuable 
information and a unique normative guide on the rationality of practical actions. Their participation in the process of deliberation and optimisation is crucial because they are the psychophysical devices by which the human being is able to discover the perfectionist criterion of practical actions and, therefore, to justify their rationale.

\section{BiBLIOGRAPHY}

Audi, R. (1993). The structure of justification Cambridge: Cambridge University Press. Audi, R. (2001). The Architecture of reason: the structure and substance of rationality. New York: Oxford University Press.

Arenas Dolz, F. (2007). «Hermenéutica, retórica y ética del lógos: deliberación y acción en la filosofía de Aristóteles», Tesis doctoral. València: Universitat de València, Servei de Publicacions.

Aristóteles (1999). Ética a Nicómaco. Madrid: Centro de Estudios Políticos y Constitucionales.

Aristóteles (2007). Retórica. Madrid: Alianza Editorial.

Brown H. I. (1988). Rationality. New York: Routledge, 1988

Elster, J. (1988). Uvas amargas: sobre la subversión de la racionalidad. Barcelona: Edicions 62.

Hanna, R. (2006). Rationality and logic. Cambridge, Mass.: MIT Press, 2006.

Rescher, N. (1988). Rationality: a philosophical inquiry into the nature and the rationale of reason. Oxford: University Press.

Snell, B. (1953). The discovery of the mind: the Greek origins of European thought. Oxford: Basil Blackwell.

Universidad Complutense de Madrid

Lydia de Tienda Palop

lydiadet@ucm.es

[Artículo aprobado para publicación en febrero de 2021] 